Acta Sci. Pol. Technol. Aliment. 15(3) 2016, 257-265

pISSN 1644-0730

eISSN 1889-9594

DOI: $10.17306 /$ J.AFS.2016.3.25

ORIGINAL PAPER

Received: 8.02.1016

Accepted: 9.08.2016

\title{
THE EFFECT OF THERMAL TREATMENT \\ ON ANTIOXIDANT CAPACITY AND PIGMENT CONTENTS IN SEPARATED BETALAIN FRACTIONS
}

\author{
Katarzyna Mikołajczyk-Bator ${ }^{\bowtie}$, Sylwia Pawlak \\ Department of Natural Science and Quality Assurance, Poznań University of Economics and Business \\ Niepodległości 10, 61-875 Poznań, Poland
}

\begin{abstract}
Background. Increased consumption of fruits and vegetables significantly reduces the risk of cardio-vascular disease. This beneficial effect on the human organism is ascribed to the antioxidant compounds these foods contain. Unfortunately, many products, particularly vegetables, need to be subjected to thermal processing before consumption. The aim of this study was to determine the effect of such thermal treatment on the antioxidant capacity and pigment contents in separated fractions of violet pigments (betacyanins) and yellow pigments (betaxanthins and betacyanins).

Material and methods. Fractions of violet and yellow pigments were obtained by separation of betalain pigments from fresh roots of 3 red beet cultivars using column chromatography and solid phase extraction (SPE). The betalain pigment content was determined in all samples before and after thermal treatment $\left(90^{\circ} \mathrm{C} / 30 \mathrm{~min}\right)$ by spectrophotometry, according to Nilsson's method [1970] and antioxidant capacity was assessed based on ABTS. Betalain pigments in the separated fractions were identified using HPLC-MS.

Results. After thermal treatment of betacyanin fractions a slight, but statistically significant degradation of pigments was observed, while the antioxidant capacity of these fractions did not change markedly. Losses of betacyanin content amounted to $13-15 \%$ depending on the cultivar, while losses of antioxidant capacity were approx. 7\%. HPLC/MS analyses showed that before heating, betanin was the dominant pigment in the betacyanin fraction, while after heating it was additionally 15-decarboxy-betanin. Isolated fractions of yellow pigments in red beets are three times less heat-resistant than betacyanin fractions. At losses of yellow pigment contents in the course of thermal treatment reaching $47 \%$, antioxidant capacity did not change markedly (a decrease by approx. 5\%). In the yellow pigment fractions neobetanin was the dominant peak in the HPLC chromatogram, while vulgaxanthin was found in a much smaller area, whereas after heating additionally 2-decarboxy-2,3-dehydro-neobetanin was detected.

Conclusion. Both groups of betalain pigments (betacyanins and betaxanthins) exhibit antioxidant capacity before and after heating. Violet beatacyjanins are 3 times more stable when heated than yellow betaxanthins.
\end{abstract}

Key words: betalain pigments, red beet, thermal treatment, antioxidant capacity

\footnotetext{
* The project was financed by the National Science Centre decision number DEC-2012/07/B/NZ9/00047.
}

『katarzyna.mikolajczyk-bator@ue.poznan.pl 


\section{INTRODUCTION}

Plant origin food contains numerous components, which along with supplying nutrients and energy may also have a health-promoting effect on the human organism. This health-promoting effect of food may be ensured thanks to increased content of a nutrient or bioactive non-nutrients, e.g. pigments. These components delay ageing processes and reduce the risk of disease (Czapski and Górecka, 2014).

Red beet is a vegetable consumed in large amounts throughout the year, cheap and readily available on the Polish market. This material is a valuable source of bioactive compounds, which exhibit several beneficial properties, e.g. antioxidant, anti-inflammatory and anticancer effects. Betalain and food products manufactured from red beet exhibit powerful anti-cancer activity. Red beet cultivars listed in the Polish national register kept at COBORU (the Research Centre of Cultivar Testing) differ in their composition and concentrations of bioactive compounds, which may affect their biological properties.

The health-promoting properties of red beet result from their betalain pigment, triterpene saponin and polyphenol content, among other things (Escribano et al., 1998; Mikołajczyk-Bator, 2015; Ravichandran et al., 2012). Betalains are classified as cation antioxidants, while betacyanins are good electron donors, thanks to the presence of a phenol group $(-\mathrm{OH})$ at position $\mathrm{C} 6$ and an amine group $(-\mathrm{NH})$ in the ring (Strack et al., 2003) and may act as free radical scavengers (Pedreno and Escribano, 2000). Betanin has one phenol group, which provides it with antioxidant properties. Such properties may also be found in the products of its degradation, e.g. neobetanin or cyclo-DOPA.

Betalains are divided into two groups: purple betacyanins (Latin Beta, beet; Greek kyanos, blue colour), and yellow betaxanthins (Latin Beta; Greek xanthos, yellow colour) (Strack et al., 2003).

These pigments are secondary metabolites synthesized from an amino acid, tyrosine, in plants from the Order Carophyllales, except for two families: Caryophyllaceae and Molluginacea (Sepulveda-Jimenez et al., 2004). The presence of betalains in plants from the Order Caryophyllales excludes the presence of anthocyanin pigments.
Beetroot pigments have a heterocyclic ring structure with a nitrogen atom in the molecule. The betalain structure has a chromophore system of three conjugated double bonds, betalamic acid. As a result of condensation, a cyclo-DOPA molecule containing an aromatic ring may be attached to betalamic acid, causing an extension of the conjugated double bond system and producing purple-colored betanidin. In turn, condensation of betalamic acid with amino acids produces yellow pigments. Maximum light absorption for most betacyanins ranges from 505 to $540 \mathrm{~nm}$, except for neobetanin and 17-decarboxy-neobetanin, 2,17-bidecarboxy-neobetanin and 2-decarboxy-2,3-dehydro-neobetanin, for which maximum light absorption ranges from 420 to $464 \mathrm{~nm}$ (Nemzer et al., 2011). Despite the yellow-orange color, these compounds are classified as betacyanins due to their chemical structure. In turn, for yellow betaxanthins maximum light absorption is approx. $470 \mathrm{~nm}$.

Beetroot contains mainly betanin, with isobetanin, prebetanin and neobetanin found in smaller amounts (Stintzing et al., 2004).

Betalain pigment content in fresh beetroot juice ranges from 0.8 to $1.3 \mathrm{~g} / \mathrm{L}$ (Wruss et al., 2015), those of purple pigments in the roots of red beet range from 30 to $300 \mathrm{mg} / \mathrm{g}$ f.m., while yellow pigments are found at 20 up to $140 \mathrm{mg} / \mathrm{g}$ f.m. (Czapski and Górecka, 2014). Their levels are dependent on genetic traits, climatic and cultivation conditions, as well as the size and parts of the root. Apart from betalain pigments red beets contain small amounts of hydroxycinnamic acids such as gallic, syringic and caffeic acids, as well as flavonoids (Kazimierczak et al., 2014), and triterpene saponins, which constitute a numerous group of compounds with a highly diverse chemical structure, being $O$-glycoside derivatives of 4 different aglycones, i.e. oleanolic acid, hederagenin, akebonoic acid and gipsogenin, to which atypical substituents may be attached, e.g. the dioxolanic substituent (Mikołajczyk-Bator et al., 2016).

Red beet is a rich source of betalain pigments for the food industry, the main such source in Poland. The fruit and vegetable processing industry uses this vegetable in the production of beetroot with horseradish, preserves, frozen vegetables, soups, juices and drinks. Red beet juice processed into concentrate or dried may be used to produce borscht concentrates 
and as pigment preparations used to dye products of weak acid and neutral reaction, such as dairy products, confectionary (including jams) or processed meats (Georgiev et al., 2010; Zielińska-Przyjemska et al., 2009).

Red beet is consumed mainly after processing, in the course of which the betalain structure and antioxidant properties of this raw material are changed. During thermal treatment betanin may be degraded as a result of isomerization, decarboxylation or dehydrogenation (Herbach et al., 2004). Most available literature data concern the assessment of activity in extracts from plants rich in betalain pigments or purified pigments, most typically by gel column chromatography. It is very difficult to produce pigments in the pure form due to their high lability. To date there has been a limited body of information concerning the antioxidant capacity of purified betalains, particularly yellow pigments.

The aim of this study was to determine the effect of thermal treatment on antioxidant capacity and pigment contents in separated fractions of violet pigments (betacyanins) and yellow pigments (betaxanthins and betacyanins).

\section{MATERIAL AND METHODS}

\section{Materials}

The material for analysis comprised fractions of violet pigments separated from yellow pigments, obtained from fresh roots of red beet cultivars Bonel, Chrobry and Nochowski, which were harvested in the 2014 season. Fresh red beetroots came from the Seed Breeding and Horticultural Station "Spójnia" at Nochowo (Poland).

\section{Isolation and separation of violet and yellow pigments}

The roots of individual red beet cultivars were washed, sliced and lyophilized, and after grinding, the lyophilizate of beetroots was defatted with diethyl ether in an Soxhlet apparatus for $18 \mathrm{~h} .100 \mathrm{~g}$ of defatted material was subjected to multiple extraction with $80 \%$ methanol solution in an ultrasound bath at $20^{\circ} \mathrm{C}$. The ratio of solvent (methyl alcohol) to plant material was 10:1. Such extracts were combined and evaporated at $35^{\circ} \mathrm{C}$ in a vacuum evaporator to produce a thick syrup.
$56 \mathrm{~mL}$ of the condensed extract (beet molasses) was transferred onto a LiChroprep RP 18 (40-63 $\mu \mathrm{m}$, Merck, Darmstadt, Germany) bed pre-conditioned with methanol followed by water, and eluted with distilled water, first eluting sugars, then violet betacyanins and finally, yellow pigments. Subsequently, the bed was rinsed with pure methanol. Eluting fractions containing violet pigments and the fractions of yellow pigments were condensed in an evaporator under reduced pressure and purified by Solid Phase Extraction (SPE) on a Sep-Pak C-18 column (5 g cartridges with $5 \mathrm{~g}$ of Lichrolut, Merck) pre-conditioned with methanol and followed by water. The Sep-Pak C-18 column was rinsed with water eluting from each fraction, initially the rest of the sugar and proteins and subsequently, purified pigments. The fractions of violet betacyanins and yellow pigments (betaxanthins and betacyanins) from three beet cultivars obtained in this way were condensed, obtaining the same pigments content (Table 1 and 2) in the solutions of the three beet cultivars tested. Separation of betalain pigments was carried out in three replications.

\section{Thermal treatment of separated pigments}

The aqueous solution of pigment fractions was sealed in glass vials and heated at $90^{\circ} \mathrm{C}$ for $30 \mathrm{~min}$. In all samples before and after thermal treatment, the betalain pigment content was determined by spectrophotometry, in accordance with Nilsson's method [1970], while antioxidant capacity was assessed using ABTS (Re et al., 1999). After thermal treatment, the samples were cooled to $25^{\circ} \mathrm{C}$ and immediately analysed.

\section{Determination of betalain pigments contents in separated fractions}

Betalain pigments were assayed by differential spectrophotometry following Nilsson's method [1970]. The fractions were diluted with a phosphate buffer (pH 6.5) and absorbance was measured at $476 \mathrm{n}$ for yellow pigments and at $538 \mathrm{~nm}$ for red pigments using a Helios Alfa spectrophotometer (Thermo Electron Corporation, USA).

\section{Antioxidant capacity of separated violet and yellow pigments fractions}

The antioxidant capacity of the pigment fractions was established using a ABTS cation radical method, 
which consists in determining the antioxidant capacity based on the scavenging rate of $\mathrm{ABTS}^{+}$radicals formed previously during chemical reactions with potassium peroxysulfate $\mathrm{K}_{2} \mathrm{O}_{8} \mathrm{~S}_{2}$. Radicals formed in this reaction are blue-green in color, while antioxidants were added by reducing the ABTS cation radical (2,2'-azinobis-(3-ethylbenzthiazoline-6-sulphonic acid), resulting in the color of solution fading, whose rate is dependent on the contents of antioxidants in the solution (Re et al., 1999). A regression equation was formulated based on the linear dependence of the percentage reduction of the ABTS cation radical on the concentration of the betacyanin or betaxanthin solution. Coefficients from the regression equation of the solutions tested and from the standard curve established for Trolox were used to calculate the TEAC values of individual fractions of violet and yellow pigments in $\mu \mathrm{mol}$ Trolox per $1 \mathrm{~cm}^{3}$ of the betacyanin or betaxanthin solution.

\section{HPLC analysis}

Pigments in separated fractions were identified before and after heating using high performance liquid chromatography coupled with mass spectrometry (HPLC/ MS) in a Waters ZQ chromatograph, based on the methodology proposed by Stintzing et al. (2003). The following HPLC separation conditions were applied: in the first 15 minutes an isocratic elution with water $/ 10 \% \mathrm{HCOOH}(95: 5, \mathrm{v} / \mathrm{v})$ was used, and then from 15 mins up to 60 mins, a $0-20 \%$ water/acetonitrile gradient $(20: 80, \mathrm{v} / \mathrm{v})$. The molecular mass of individual pigments in the separated fractions was determined by Electrospray Ionization (ESI). Qualitative identification of individual pigments in separated fractions was performed based on a comparison of retention times and analyses of the spectra of separated compounds with literature data.

The UV-VIS spectra of separated and purified fractions were prepared both before and after thermal treatment and on the basis of these spectra, the purity of the separated pigments was verified (Fig. 1A, 1B).

\section{Statistical analysis}

Differences between means were assessed using the one-way analysis of variance at the significance level $\alpha=0.05$. The uncertainty of TEAC measurements was evaluated based on the plotted curves using the least squares method. All analyses were conducted in three independent replications, data were described to produce the standard deviation $( \pm \mathrm{SD})$. Calculations were made using the Microsoft Excel spreadsheet.

In order to determine differences between the level of violet and yellow pigments in the separated fractions before and after heating, as well as the antioxidant capacity of unheated and heated fractions, a two-way analysis of variance was applied and the hypotheses were verified at the significance level $\alpha=0.05$ using a Microsoft Excel spreadsheet. The following hypotheses were verified: the fractions differ in their pigment content before and after heating. The separated pigment fractions differ in terms of their antioxidant capacity before and after heating.

\section{RESULTS AND DISCUSSION}

Application of column chromatography on the LiChroprep RP-18, 40-63 $\mu \mathrm{m}$ bed followed by purification of isolated betalain fractions by solid phase extraction (SPE) made it possible to separate violet and yellow pigments from the roots of three red beet cultivars Bonel, Chrobry and Nochowski (Fig. 1A, 1B).

In the reverse phase (RP) system, both medium and non-polar secondary metabolites bind to the bed used in the experiment, i.e. silica gel modified with octadecyl groups $\mathrm{C} 18$. Highly polar compounds, i.e. sugars, were the first to be eluted from the column with water, and they were followed by less polar violet betacyanins and finally, by yellow betaxanthins and yellow-orange betacyanins. Betaxanthins and yellow-orange betacyanins (neobetanin and its derivatives) are less polar pigments than violet betacyanins, for this reason they were eluted from the column after violet betacyanins. Fractions of violet betacyanins separated from yellow pigments required further purification and for this reason Sep-Pak C18 extraction columns were used. Individual pigment fractions previously isolated on the LiChroprep bed were transferred onto Sep-Pak C18 columns and then eluted with distilled water. This method facilitated relatively easy purification and simultaneous deproteinization of individual fractions. The eluates produced from the Sep-Pak column comprised purified fractions of violet betacyanins or yellow betaxanthins and yellow-orange betacyanins, which were condensed in an evaporator until identical pigment contents were obtained in all the samples tested. 


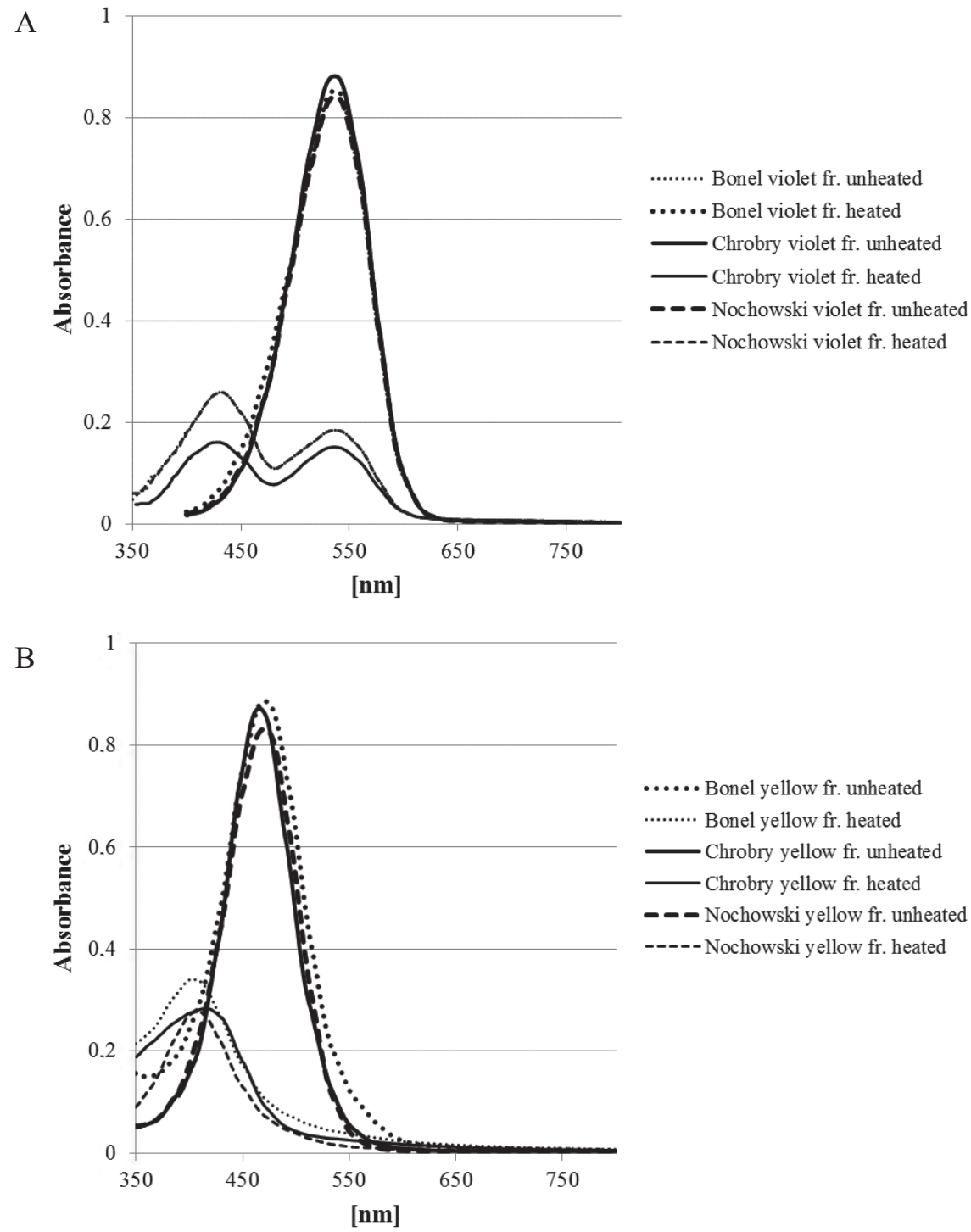

Fig. 1. Spectra of the (A) violet and (B) yellow pigment fraction in three red beet cultivars before and after thermal treatment at $90^{\circ} \mathrm{C} / 30 \mathrm{~min}$ within the range of UV-VIS visible light

The violet betacyanins isolated from the three beet cultivars amounted to 102,103 and $100 \mathrm{mg} / 100 \mathrm{~cm}^{3}$, respectively, for cv. Bonel, Chrobry and Nochowski. The antioxidant capacity of these fractions was 7.92, 7.74 and $7.70 \mu \mathrm{M}$ Trolox $/ \mathrm{cm}^{3}$, respectively (Table 1).

Within the separated fraction of violet pigments, the following were identified before thermal treatment: betanin with $\mathrm{m} / \mathrm{z} 551[\mathrm{M}+\mathrm{H}]^{+}$, 15-decarboxy-betanin with $\mathrm{m} / \mathrm{z} 507[\mathrm{M}+\mathrm{H}]^{+}$and betanidin with $\mathrm{m} / \mathrm{z} 389$ $[\mathrm{M}+\mathrm{H}]^{+}$, while after heating a product of betanidin degradation with $\mathrm{m} / \mathrm{z} 297[\mathrm{M}+\mathrm{H}]^{+}$was also detected.

In the separated fraction of yellow pigments before heating vulgaxanthin I with $\mathrm{m} / \mathrm{z} 341[\mathrm{M}+\mathrm{H}]^{+}$, dopamine-bx (miraxanthin V) with $\mathrm{m} / \mathrm{z} 347[\mathrm{M}+\mathrm{H}]^{+}$, neobetanin with $\mathrm{m} / \mathrm{z} 549[\mathrm{M}+\mathrm{H}]^{+}$were identified, while after thermal treatment an ion was also detected with $\mathrm{m} / \mathrm{z} 503[\mathrm{M}+\mathrm{H}]^{+}$corresponding to 
Mikołajczyk-Bator, K., Pawlak, S. (2016). The effect of thermal treatment on antioxidant capacity and pigment contents in separated betalain fractions. Acta Sci. Pol. Technol. Aliment., 15(3), 257-265. DOI: 10.17306/J.AFS.2016.3.25

Table 1. Contents of betalain pigments and antioxidant capacity of the separated violet pigment fraction

\begin{tabular}{|c|c|c|c|c|}
\hline \multirow{2}{*}{$\begin{array}{l}\text { Red beet } \\
\text { cultivar }\end{array}$} & \multicolumn{2}{|c|}{$\begin{array}{c}\text { Content of betacyanins } \\
\text { by Nilsson } \\
\mathrm{mg} / 100 \mathrm{~cm}^{3}\end{array}$} & \multicolumn{2}{|c|}{$\begin{array}{c}\text { TEAC } \\
\mu \mathrm{M} \text { Trolox } / \mathrm{cm}^{3}\end{array}$} \\
\hline & $\begin{array}{l}\text { before } \\
\text { thermal } \\
\text { treatment }\end{array}$ & $\begin{array}{c}\text { after } \\
\text { thermal } \\
\text { treatment }\end{array}$ & $\begin{array}{l}\text { before } \\
\text { thermal } \\
\text { treatment }\end{array}$ & $\begin{array}{c}\text { after } \\
\text { thermal } \\
\text { treatment }\end{array}$ \\
\hline Bonel & $\begin{array}{c}102.1^{\mathrm{bB}} \\
( \pm 0.35)\end{array}$ & $\begin{array}{r}88.9^{\mathrm{bA}} \\
( \pm 0.35)\end{array}$ & $\begin{array}{c}7.92^{\mathrm{fE}} \\
( \pm 0.05)\end{array}$ & $\begin{array}{c}7.48^{\mathrm{fD}} \\
( \pm 0.10)\end{array}$ \\
\hline Chrobry & $\begin{array}{l}103.0^{\mathrm{cB}} \\
( \pm 0.27)\end{array}$ & $\begin{array}{c}87.8^{\mathrm{cA}} \\
( \pm 0.42)\end{array}$ & $\begin{array}{c}7.74^{\mathrm{eE}} \\
( \pm 0.09)\end{array}$ & $\begin{array}{c}7.16^{\mathrm{eD}} \\
( \pm 0.08)\end{array}$ \\
\hline Nochowski & $\begin{array}{l}100.3^{\mathrm{aB}} \\
( \pm 0.38)\end{array}$ & $\begin{array}{r}85.0^{\mathrm{aA}} \\
( \pm 0.26)\end{array}$ & $\begin{array}{c}7.70^{\mathrm{dE}} \\
( \pm 0.03)\end{array}$ & $\begin{array}{c}7.15^{\mathrm{dD}} \\
( \pm 0.05)\end{array}$ \\
\hline
\end{tabular}

${ }^{*}$ Thermal treatment conditions $-90^{\circ} \mathrm{C} / 30 \mathrm{~min}$.

\pm - standard deviation.

${ }^{a-c}$ Violet pigment content does not differ significantly between cultivars (no significant differences between means in rows).

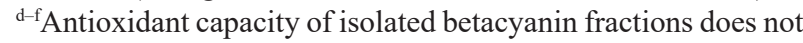
differ significantly between cultivars (no significant differences between means in rows).

${ }^{A-B}$ Purple pigment content differs significantly in unheated and heated fractions (significant differences between means in columns).

${ }^{\mathrm{D}-\mathrm{E}}$ Antioxidant capacity of isolated betacyanin fractions does not differs significantly before and after heating (no significant differences between means in columns).

2-decarboxy-2,3-dehydro-neobetanin. We need to stress the fact that in the separated fraction of yellow pigments of red beets the dominant pigment was neobetanin, structurally classified as a violet pigment (betacyanin). This compound is yellow-orange in color and it was eluted on a LiChroprep RP-18 40-63 $\mu \mathrm{m}$ bed together with yellow betaxanthins, due to its lower polarity than betanin. Neobetanin is found in red beets as a natural substance of its raw material or it may be formed as a result of the transformation of betanin to neobetanin through dehydrogenation under the influence of elevated temperature (Herbach et al., 2006).

Thermal treatment had a significant effect on violet betacyanin content but not on their antioxidant capacity. During thermal treatment of betacyanin fractions their level decreased by $13 \%$ up to $15 \%$ depending on the cultivar (Table 1).

Despite losses of violet pigments (betacyanins) in the course of thermal treatment ranging from $13 \%$ to
$15 \%$ depending on the analyzed cultivar, antioxidant capacity fluctuated slightly (by approx. 5-7\% depending on the cultivar). The antioxidant capacity of isolated betacyanin fractions does not differs significantly before and after heating.

During thermal treatment violet betacyanins were degraded, as was evident in the UV-VIS spectrum in the reduction of light maximum absorption on the wavelength $\lambda=538 \mathrm{~nm}$.

At the same time, a new band was observed with an absorption maximum at $\lambda=430 \mathrm{~nm}$ (Fig. 1), which, using HPLC-MS analyses, was identified as a product of betanidin degradation yielding an ion with $\mathrm{m} / \mathrm{z} 297$ $[\mathrm{M}+\mathrm{H}]^{+}$(Fig. 2B). The high antioxidant capacity of heated fractions is the sum of pigments found in the fractions after heating, in which neobetanin and 2-decarboxy-2,3-dehydro-neobetanin were found in the greatest amounts. In the experiment it was found that

Table 2. Contents of betalain pigments and antioxidant capacity of the separated yellow pigment fraction

\begin{tabular}{|c|c|c|c|c|}
\hline \multirow{2}{*}{$\begin{array}{l}\text { Red beet } \\
\text { cultivar }\end{array}$} & \multicolumn{2}{|c|}{$\begin{array}{c}\text { Content of betxanthins } \\
\text { by Nilsson } \\
\mathrm{mg} / 100 \mathrm{~cm}^{3}\end{array}$} & \multicolumn{2}{|c|}{$\begin{array}{c}\text { TEAC } \\
\mu \mathrm{M} \text { Trolox } / \mathrm{cm}^{3}\end{array}$} \\
\hline & $\begin{array}{l}\text { before } \\
\text { thermal } \\
\text { treatment }\end{array}$ & $\begin{array}{c}\text { after } \\
\text { thermal } \\
\text { treatment }\end{array}$ & $\begin{array}{l}\text { before } \\
\text { thermal } \\
\text { treatment }\end{array}$ & $\begin{array}{c}\text { after } \\
\text { thermal } \\
\text { treatment* }\end{array}$ \\
\hline Bonel & $\begin{array}{l}101.1^{\mathrm{aB}} \\
( \pm 0.41)\end{array}$ & $\begin{array}{c}61.2^{\mathrm{aA}} \\
( \pm 0.43)\end{array}$ & $\begin{array}{c}7.24^{\mathrm{dE}} \\
( \pm 0.06)\end{array}$ & $\begin{array}{c}6.98^{\mathrm{dD}} \\
( \pm 0.06)\end{array}$ \\
\hline Chrobry & $\begin{array}{l}103.2^{\mathrm{cB}} \\
( \pm 0.10)\end{array}$ & $\begin{array}{c}59.6^{\mathrm{cA}} \\
( \pm 0.35)\end{array}$ & $\begin{array}{c}7.49^{\mathrm{fE}} \\
( \pm 0.07)\end{array}$ & $\begin{array}{c}7.13^{\mathrm{fD}} \\
( \pm 0.06)\end{array}$ \\
\hline Nochowski & $\begin{array}{l}102.5^{\mathrm{bB}} \\
( \pm 0.40)\end{array}$ & $\begin{array}{c}53.8^{\mathrm{bA}} \\
( \pm 0.39)\end{array}$ & $\begin{array}{c}7.34^{\mathrm{eE}} \\
( \pm 0.01)\end{array}$ & $\begin{array}{c}7.01^{\mathrm{eD}} \\
( \pm 0.02)\end{array}$ \\
\hline
\end{tabular}

*Thermal treatment conditions $-90^{\circ} \mathrm{C} / 30 \mathrm{~min}$.

\pm- standard deviation.

${ }^{a-c}$ Yellow pigment content does not differ significantly between cultivars (no significant differences between means in rows).

${ }^{\mathrm{d}-\mathrm{f}}$ Antioxidant capacity of isolated yellow fractions does not differ significantly between cultivars (no significant differences between means in rows).

${ }^{A-B}$ Yellow pigments content differs significantly in unheated and heated fractions (significant differences between means in columns).

${ }^{\mathrm{D}-\mathrm{E}}$ Antioxidant capacity of isolated yellow fractions does not differs significantly before and after heating (no significant differences between means in columns). 
the antioxidant capacity of betacyanins after thermal treatment decreased by as little as $5-7 \%$. The products of violet betacyanin degradation forming during thermal treatment exhibit high antioxidant capacity.

Studies conducted by other authors indicate that during thermal treatment as a result of decarboxylation or dehydrogenation, betanin (a violet pigment found in greatest amounts in beets) is transformed into neobetanin and/or its derivatives (yellow-orange pigments), which are classified to violet pigments (betacyanins) due to their chemical structure. Neobetanin and its derivatives show maximum light absoprtion within the range from 420 to $464 \mathrm{~nm}$, i.e. they are yellow-orange in color, despite being classified to the group of violet betacyanins, as a result of their chemical structure.

In red beet Nemzer et al. (2011) identified not only neobetanin, but also 17-decarboxy-neobetanin, 2,17-bidecarboxy-neobetanin and 2-decarboxy-2,3-dehydro-neobetanin with the maximum light absorption at $420-464 \mathrm{~nm}$, as degradation products formed during thermal treatment (Nemzer et al., 2011). The directions of betalain changes result from the processes occurring, such as decarboxylation, dehydrogenation, hydrolysis and deglycosylation. Decarboxylation may occur at $\mathrm{C} 2, \mathrm{C} 15$ and $\mathrm{C} 17$ in the betacyanin molecule, while in the case of betaxanthins it is at $\mathrm{C} 11$ and $\mathrm{C} 12$ (Wybraniec, 2005; Wybraniec and Mizrahi, 2005).

Dehydrogenation of betanin takes place at the carbon atom $\mathrm{C}-2,3, \mathrm{C} 14$ and $\mathrm{C} 15$ in the betalamic acid ring, producing a double bond between $\mathrm{C} 14$ and $\mathrm{C} 15$ of the neobetanin ring (Stintzing and Carle, 2004).

In the case of the separated yellow pigments fraction, the losses of content after thermal treatment range from 39 to $47 \%$, depending on the cultivar analyzed, while antioxidant capacity fluctuated slightly.

In the fraction of yellow pigments after thremal treatment, apart from vulgaxanthin I with $\mathrm{m} / \mathrm{z} 341$ $[\mathrm{M}+\mathrm{H}]^{+}$, dopamine-bx (miraxanthin $\mathrm{V}$ ) with $\mathrm{m} / \mathrm{z} 347$ $[\mathrm{M}+\mathrm{H}]^{+}$and neobetanin with $\mathrm{m} / \mathrm{z} 549[\mathrm{M}+\mathrm{H}]^{+}$, 2-decarboxy-2,3-dehydro-neobetanin with $\mathrm{m} / \mathrm{z} 503$ $[\mathrm{M}+\mathrm{H}]^{+}$was also detected. The presence of this pigment caused a shift in the absorption maximum of the yellow pigment fraction from $472 \mathrm{~nm}$ to approx, $410 \mathrm{~nm}$, observed in the UV-VIS spectrum (Fig. 2).

This pigment was formed as a result of decarboxylation and dehydrogenation of neobetanin found in the unheated fraction. Decarboxylation consisted in the loss of the carboxyl group found on the carbon atom at position $\mathrm{C} 2$ in the neobetanin ring, whereas dehydrogenation consisted in the loss of two protons on the carbon atom at positions $\mathrm{C} 2$ and $\mathrm{C} 3$ of the neobetanin ring under the influence of thermal treatment.

The dominant peaks in the HPLC chromatogram of the yellow pigment fraction after heating were those of neobetanin and 2-decarboxy-2,3-dehydro-neobetanin. Products of the thermal degradation of yellow pigments fractions exhibit a high antioxidant capacity. The reduction in the antioxidant capacity in the yellow pigment fraction amounted to as little as $4.5-5 \%$ depending on the cultivar (Table 2). In comparison to the violet betacyanin fractions, the fractions of yellow pigments (betaxanthins and betacyanins) are almost three times less resistant to elevated temperature and their losses during thermal treatment were much greater in comparison to the losses of violet betacyanins. Thermal treatment had a statistically significant effect in that it decreased yellow pigments content (Table 1).

The technological processes applied, including thermal treatment, may have a varied effect on the quality of plant origin food, reducing or enhacing its antioxidant potential (Kidoń and Czapski, 2007), whereas in the case of red beets heating had a significant effect, decreasing the content of violet and yellow pigments in the separated fractions, with greater losses of pigments recorded in the fractions containing yellow pigments. Heating separated fractions of violet and yellow beet pigments at $90^{\circ} \mathrm{C}$ for 30 minutes only slightly reduced their antioxidant capacity.

\section{CONCLUSIONS}

The application of column chromatography on the Lichroprep 40-63 $\mu \mathrm{m}$ bed coupled with solid phase extraction (SPE) results in a complete separation of the betalain mixture into two main groups of pigments, i.e. violet pigments and yellow pigments.

Violet betacyanin fractions isolated from red beet roots exhibit antioxidant capacity, both before and after thermal treatment. During thermal treatment, betacyanins in the fraction are degraded. At a $15 \%$ loss of betacyanin, antioxidant capacity decreased only by approx. $7 \%$.

Yellow pigment fractions are three times less resistant to thermal treatment than violet betacyanin 


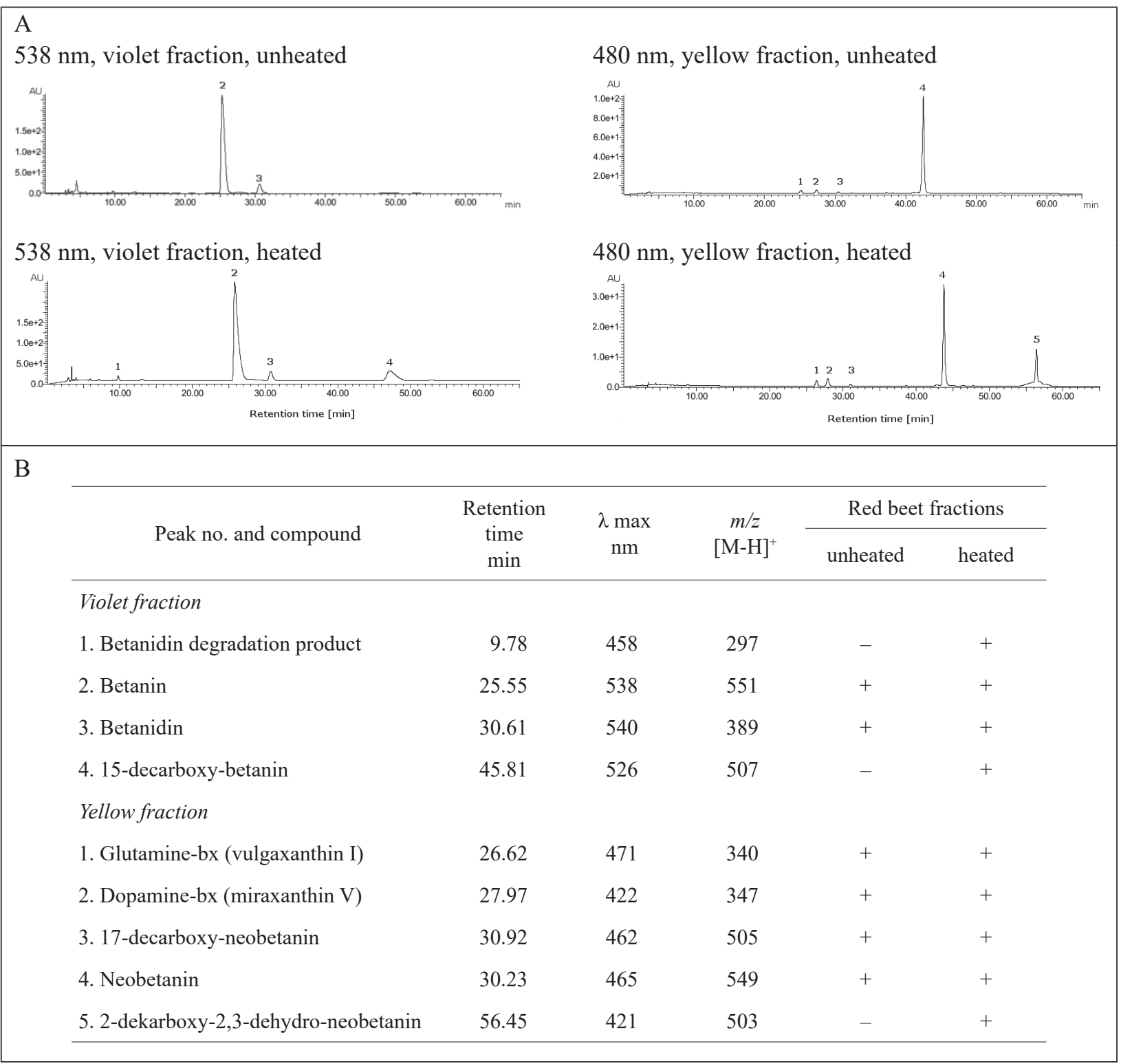

Fig. 2. A - HPLC chromatogram of violet and yellow fraction of red beet (Beta vulgaris L.) cv. Nochowski, before and after thermal treatment $\left(90^{\circ} \mathrm{C} / 30 \mathrm{~min}\right) . \mathbf{B}$ - Peak numbers refer to compounds shown in the table below. Chromatographic, spectrophotometric and mass spectrometric data of the pigments found in the red beet fractions

fractions. Despite considerable loss of yellow pigment, amounting to as much as $47 \%$, during the course of thermal treatment antioxidant capacity decreased slightly - by approx. $5 \%$.

The dominant compounds in the fraction of violet pigments after thermal treatment were betanin and 15-decarboxy-betanin, whereas in the yellow pigment fraction after heating it was neobetanin and 2-decarboxy-2,3-dehydro-neobetanin. Products of thermal degradation of betalain pigment fractions exhibit a high antioxidant capacity. Red beet pigments are valuable sources of natural antioxidants, while fresh or heated products with the addition of beet pigments may provide to be a health-promoting food. 


\section{REFERENCES}

Czapski, J., Górecka, D. (2014). Żywność prozdrowotna. Składniki i technologia [Health-promoting food. Components and technology]. Poznań: Wyd. UP [in Polish].

Escribano, J. Pedreno, M. A., Garcia-Carmona, F., Munoz, R. (1998). Characterization of the antiradical activity of betalains from Beta vulgaris L. roots. Phytochem. Anal., 9, 124-126.

Georgiev, V. G., Weber, J., Kneschke, E. M., Denev, P. N., Bley, T., Pavlov, A. I. (2010). Antioxidant activity and phenolic content of betalain extracts from intact plants and hairy root cultures of the red beetroot Beta vulgaris cv. Detroit dark red. Plant Food Hum. Nutr., 62(2), $105-111$.

Herbach, K. M., Stintzing, F. C., Carle, R. (2006). Betalain stability and degradation - structural and chromatic aspects. J. Food Sci., 71(4), 41-50.

Herbach, K. M., Stintzing, F. C., Carle, R. (2004). Impact of thermal treatment on color and pigment pattern of red beet (Beta vulgaris L.) preparations. Food Chem. Toxicol., 69(6), 491-498.

Kazimierczak, R., Hallmann, E., Lipowski, J., Drela, N., Kowalik, A, Pussa, T., Matt, D., Luik, A., Gozdowski, D., Rembia, X. K. E. (2014). Beetroot (Beta vulgaris L.) and naturally fermented beetroot juice from organic and conventional production: metabolomics, antioxidant levels and anti-cancer activity. J. Sci. Food Agric., 94(13), 2618-2629.

Kidoń, M., Czapski, J. (2007). Wpływ obróbki termicznej na zawartość barwników betalainowych i zdolność przeciwutleniającą buraka ćwikłowego [The effect of thermal treatment on contents of betalain pigments and antioxidant capacity of beetroot]. Żywn. Nauka Techn. Jakość, 1(50), 124-131 [in Polish].

Mikołajczyk-Bator, K. (2015). Antioxidant activity of triterpene saponins from red beet. BACIF International Conference. Abstracts. 15-16 October, Łódź, 28.

Mikołajczyk-Bator, K., Błaszczyk, A., Czyżniejewski, M., Kachlicki, P. (2016). Characterization and identification of triterpene saponins in the roots of red beet (Beta vulgaris L.) using two HPLC-MS systems. Food Chem., 192, 979-990.

Nemzer, B., Pietrzkowski, Z., Spórna, A., Stalica, P., Thresher, W., Michałowski, T., Wybraniec, S. (2011). Betalainic and nutritional profiles of pigment-enriched red beet root (Beta vulgaris L.) dried extracts. Food Chem., 127, 42-53.
Nilsson, T. (1970). Studies into the pigments in beetroot (Beta vulgaris L. ssp. vulgarris var. rubra L.). Lantbrukshogskolans Annaler., 36, 179-219.

Pedreno, M. A., Escribano, J. (2000). Studying the oxidation and the antiradical activity of betalain from beetroot., J. Biol. Educ., 35, 49-51.

Ravichandran, K., Ahmed, A. R., Knorr, D., Smetanska, I. (2012). The effect of different processing methods on phenolic acid content and antioxidant activity of red beet. Food Res. Int., 48, 16-20.

Re, R., Pellegrini, N., Proteggente, A., Pannala, A., Yang, M., Rice-Evans, C. (1999). Antioxidant activity applying an improved ABTS radical cation decolorization assay. Free Radical Biol. Med., 26, 1231-1237.

Sepulveda-Jimenez, G., Rueda-Benitez, P., Porta, H., Rocha-Sosa, M. (2004). Betacyanin synthesis in red beet (Beta vulgaris) leaves induced by wounding and bacterial infiltration is preceded by an oxidative burst. Physiol. Mol. Plant P., 64, 125-133.

Stintzing, F. C., Schieber, A., Carle, R. (2003). Evaluation of colour properties and chemical quality parameters of cactus juices. Eur. Food Res. Technol., 216, 303-311.

Stintzing, F. C., Carle, R. (2004). Functional properties of anthocyanins and betalains in plants, food, and in human nutrition. Trends Food Sci. Technol., 15, 19-38.

Strack, D., Vogt, T., Schielmann, W. (2003). Recent advances in betalain research. Phytochem., 62, 247-269.

Wruss, J., Waldenberger, G., Huemer, S., Uygun, P., Lanzerstorfer, P., Müller, U., Höglinger, O., Weghuber, J. (2015). Compositional characteristics of commercial beetroot products and beetroot juice prepared from seven beetroot varieties grown in upper Austria. J. Food Compos. Anal., 42, 46-55.

Wybraniec, S., Mizrahi, Y. (2005). Generation of decarboxylated and dehydrogenated betacyanins in thermally treated purified fruit extract from purple pitaya (Hylocereus polyrhizus) monitored by monitored by LC/MS/ MS. J. Agric. Food Chem., 53, 6704-6712.

Wybraniec, S. (2005). Formation of decarboxulated betacyanins in heated purified betacyanin fractions from red beet root (Beta vulgaris L.) monitored by LC/MS/MS. J. Agric. Food Chem., 53, 3483-3487.

Zielińska-Przyjemska, M., Olejnik, A., Dobrowolska-Zachwieja, A., Grajek, W. (2009). In vitro effects of beetroot juice and chips on oxidative metabolizm and apoptosis in neutrophils from obese individuals. Phytother. Res., 23(1), 49-55. 
